\title{
Primary care professionals and social marketing of health in neighbourhoods: a case study approach to identify, target and communicate with 'at risk' populations
}

Jane Powell Faculty of Health and Social Care, University of the West of England, UK, Alan Tapp Business School,
University of the West of England, Bristol, UK, Judy Orme Faculty of Health and Social Care, University of the West of
England, UK and Marc Farr Dr Foster, London, UK and (formerly of Experian Ltd, Nottingham, UK); Lancaster University, UK

\begin{abstract}
Aim: In this article the authors illustrate using a case study approach how primary care professionals can use the combination of geodemographic data with hospital episode statistics (HES) to predict the location of people 'at risk' of diabetes mellitus (Type 2 diabetes) in the population of England. This approach facilitates social marketing of those 'at risk'. Method: Geodemographic segmentation data for all households was combined with HES for 2001-2002, to predict population groups 'at risk' of Type 2 diabetes. Using a case study approach and quantitative data analysis techniques, a profile of the undiagnosed and 'at risk' population of Slough Primary CareTrust was created at town, ward and street levels. Recent literature on social marketing was applied to predicate a discussion of the theory and practice of social marketing that was most likely to succeed in dealing with the prevention of Type 2 diabetes, via the reduction of obesity and overweight in the population. Discussion: The increase in lifestyle-related diseases, such as, Type 2 diabetes that are linked with the rise in overweight and obesity and create large disease management costs for the National Health Service (NHS) are of great concern to primary healthcare professionals and governments throughout the westernized world. Until recently, public and government responses have been very reactive in respect of population groups most in need of lifestyle change. Approaches to the identification of 'sub-populations' most at risk of Type 2 diabetes and targeting of these is of direct relevance to the preventive work of primary care professionals. Conclusion: Geodemographic data overlaid onto official NHS and other routinely collected data, can aid the identification and targeting of groups most vulnerable to overweight and obesity, through social marketing approaches including direct mail, telephone canvassing and door-to-door communication channels.
\end{abstract}

Key words: geodemographics; hospital episode statistics; MOSAIC; resources; social marketing; Type 2 diabetes

Received: January 2006; accepted: August 2006

\section{Introduction: Type 2 diabetes, lifestyle and the 'Obesity Time bomb'}

Type 2 diabetes and obesity are inextricably linked (Diabetes UK, 2005). Around 1.8 million people

\footnotetext{
Author for correspondence: Dr Jane Powell, Glenside Campus, University of the West of England, Bristol, Blackberry Hill, Stapleton, Bristol BS16 1DD, UK.
}

in the UK have been diagnosed with diabetes and 90-95\% of these cases are Type 2 diabetics (Diabetes UK, 2005). In the UK and other westernized countries the proportion of overweight and obese adults and children is increasing rapidly. While the trend has been upwards for decades, levels of obesity have increased at an alarming rate through the 1990s and 2000s in particular. In England, successive National Diet and Nutrition surveys in 1987 and 2001, have

(C) 2007 Cambridge University Press 
indicated steep rises in levels of overweight and obese people in just a few short years. In 1987, obesity prevalence rates of $8 \%$ in men and $12 \%$ in women were recorded. By 2001, prevalence increased to $17 \%$ of men and $20 \%$ of women (Office of National Statistics, 2003). The Health Survey for England in 2002 indicated that $41 \%$ of men and $33 \%$ of women were overweight and $25 \%$ of men and $20 \%$ of women were obese (Department of Health, 2003). Diabetes UK estimate that a further one million people in the UK have Type 2 diabetes, but are unaware of this and are undiagnosed.

Obesity is defined through calculation of Body Mass Index (BMI). This is a person's weight in kilograms divided by the square of the person's height in metres. In the UK, people with a BMI between 25 and 30 are categorized as overweight, and those with an index above 30 are categorized as obese (Royal College of Physicians et al., 2004) The rising tide of obesity has recently been described as a health time bomb that needs defusing (Chief Medical Officer, 2002). Increased prevalence of overweight and obese adults is of great concern to governments because of the link with ill-health through diseases, such as Type 2 diabetes, some cancers, coronary heart disease, chronic ill-health, renal failure, osteoarthritis, foot problems and eye problems. Type 2 diabetes has increased in the younger population creating potential resource allocation problems for the public sector. Future disease management is likely to be a very costly process for the National Health Service (NHS) in England if measures are not taken to reduce it soon (Wanless, 2004). As a result, tackling obesity is now regarded as of paramount importance by governments in developed countries, not just in the UK, but worldwide (International Obesity Taskforce, 2002; World Health Organisation, 2004). While the debates about causes and treatments go on, government and public bodies in the UK have united around practical measures to tackle obesity as an urgent public priority and to invite the population to become 'fully engaged' with their own good health. The opportunity cost of not achieving fullengagement was estimated in the first Wanless Report at $£ 20$ billion by 2022 (Wanless, 2002).

\section{Social marketing}

Primary healthcare professionals are increasingly interested in 'social marketing' as a way of tackling health problems that are considered 'preventative' and have an unequal spread in the population. The link between health and social marketing is complex and multi-levelled, but there has been work establishing a theoretical dimension to marketing as a positive force for better health, via the 'social marketing paradigm' (Hastings and Saren, 2003; National Social Marketing Centre for Excellence, 2005). Lefebvre and Flora (1988) (cited in Naidoo and Wills, 2005) propose the key components of social marketing as consumer orientation, identification of key audience through segmentation and analysis, voluntary and mutually beneficial exchange, formative research, clear objective setting, channel analysis, a marketing mix of product, place, promotion and monitoring evaluation. In particular, as these authors point out, marketers are keen to influence consumer behaviour - in this case the need is to influence people to adopt healthier eating and exercise habits to avoid obesity (Lefebvre and Flora, 1988; Naidoo and Wills, 2005).

This article is primarily concerned with the idea of market segmentation or grouping people together. Segmentation based on a range of attributes is central to effective social marketing (Lefebvre and Flora, 1988; Naidoo and Wills, 2005). While the language of public health discourse may not express it in these terms, the idea of 'market segmentation', is now increasingly commonplace in public health policy. In particular, there is a realization that achievement of the Derek Wanless fully engaged scenario depends upon the engagement of 'deprived and marginalized' communities; if it is to be successful. Some sections of the population experience barriers that thwart and prevent attempts to live healthy lifestyles because the circumstances and context of their lives are not conducive to health improvement. The Department of Health White Paper 'Choosing health - Making healthy choices easier' not only recognizes that people need supportive environments within which to change behaviour, but also the need for individually tailored health improvement plans (Department of Health, 2004). 'Choosing Health' recognizes the implementation of personalized 'health guides' that is practical plans for improving individual health that fit into the context of peoples lives (Department of Health, 2004). In addition, it argues for the importance of context in an individual healthy lifestyle acknowledging that this includes a whole host of socio-economic and socio-cultural factors, as well Primary Health Care Research and Development 2007; 8: 22-35 
as peoples' own attitudes and beliefs surrounding good health.

\section{Tackling obesity - bringing together public health prevention policy and social marketing}

The emphasis on prevention and health promotion and the close relationship between health and social marketing are central themes of the recent White Paper (Department of Health, 2004). The White Paper may, in a sense, be viewed as a marketing strategy which stimulates demand for health, provides accessible and credible information, guarantees a supply of local services or healthier products and ensures a local environment that makes healthy choice easier (House of Commons Health Committee, 2004). However, there is also recognition that making healthy choices is easier for some people than others and in the case of obesity, we can begin by examining socio-environmental factors and their impact on the obesogenic environment. A complex multi-layered environment is revealed, with four groups of factors contributing to increased obesity levels identified. These are: firstly the presence of 'at risk' groups in terms of medical and socio-economic factors; secondly, the presence of conditions likely to contribute to obesity levels, for example, poverty, social marginalization. Thirdly, the prevalence of risk behaviours, for example, low levels of physical activity, high-energy diets, or poor diets. Finally the presence of psychological or environmental risk factors, for example, lack of social support, exposure to food advertising, poor access to healthy food (Mulvihill and Quigley, 2003).

If, as current health policy identifies, social marketing is an important approach in future behavioural change strategies, then it is vital that market segmentation and targeting are effected as precisely as possible. This may mean segmentation that is achieved using a large number of relevant population characteristics.

The central purpose of this article is to illustrate to an audience of primary care professionals, the worth of 'an approach' to identification and targeting of 'at risk sub-populations' for Type 2 diabetes in a preventative sense. The approach combines a segmentation database of the UK population with health services data, to give direction to public health policy on reduction of Type 2 diabetes in the diagnosed and undiagnosed population in a targeted and appropriate way. From a health marketing perspective, this gives public policy makers and health professionals a platform for 'understanding wellbeing' and a practical targeting tool from which a social marketing strategy can be designed. Hence in this article we combine geodemographic data with hospital episode statistics (HES) data recorded in 2001-2002 for Type 2 diabetes (strongly linked to overweight and obesity), to generate detailed geodemographic profiles of population groups at national, city, town, ward and street levels. Our aim is to illustrate a useful approach in an appropriate way for primary care professionals and not to re-explore the previously reported Slough case study (Farr and Evans, 2005).

Geodemographic data can be applied to understand the context in which tailored behavioural interventions could be designed and how and where resources might be targeted to deliver behaviour change with social marketing initiatives. At the present time, geodemographic profiling combined with routine NHS data has not been widely used in a predictive manner to identify 'Type 2 hotspots' at various levels of population aggregation.

The authors see this work as a first step in demonstrating how existing social marketing and public health policy theory can be deployed in the 'obesity field'. A pre-understanding of the socioenvironmental factors underpinning obesity allows us to consider more in-depth models that could underpin the creation of health intervention programmes that may have a chance of success. Figure 1 is tentatively proposed as an explanation of how demographics and 'psychographics' (an individual's psychological and attitudinal make-up) may underpin behaviours linked to Type 2 diabetes and obesity.

\section{Research design and methods}

A predictive, secondary data analysis was run using HES of Type 2 diabetes for 2001-2002 with 61 appended geodemographic MOSAIC groups and type codes for all households in England.

\section{GB HES for Type 2 diabetes 2001-2002}

This dataset contains entries for 12.8 million overnight hospital admissions to all hospitals in Great Britain (GB) in 2001-2002. Each data record for admissions contains a diagnostic code indicating 


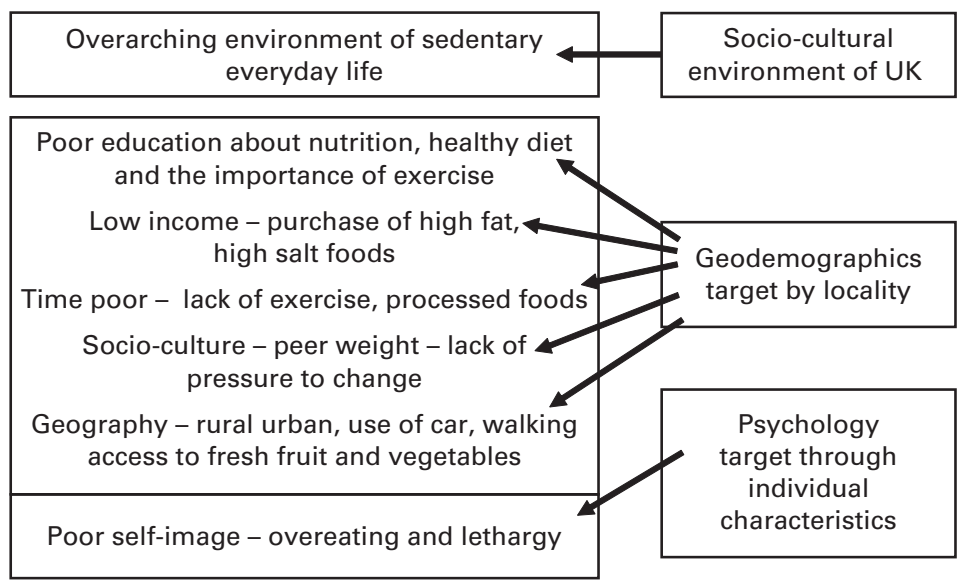

Figure 1 Factors leading to obesity

the health problem that necessitated an overnight stay in hospital. HES also record patient date of birth, ethnicity, Primary Care Trust (PCT) code, general practitioner (GP) code, local authority code and postal code.

\section{MOSAIC geodemographic classifications for all GB households}

\section{Geodemographic dataset - MOSAIC UK}

MOSAIC UK is a commercial dataset owned by Experian Ltd. The household version of MOSAIC groups households together into clusters described according to their geographic and demographic characteristics. Household MOSAIC is based on census data, housing and financial data. A total of 400 variables are used to build MOSAIC profiles and some of these are updated annually. These variables have been selected as inputs to the classification on the basis of their volume, quality, consistency and sustainability. In order to be included into the classification data must meet one or more of four criteria. First, that it allows identification and description of consumer segments that are not necessarily distinguished solely by the use of Census data. Second, the data ensures accuracy of the MOSAIC code by either household address or postcode. Third, data is current and lastly it improves discrimination of segments and allows for the identification of a wide range of consumer behaviours. Fifty-four per cent of the data used to build MOSAIC is sourced from the 2001 Census. The remaining $46 \%$ is derived from a consumer segmentation database, which provides coverage of all of the UK's 46 million adult residents and 23 million households using the Electoral Roll, lifestyle survey information, consumer credit activity, post office address file, Shareholder's Register, house price and council tax information and Office of National Statistics local area statistics. MOSAIC classifies consumers by household or by postcode which allows optimization of use of the segmentation depending on application.

\section{Procedure}

The MOSAIC data is linked to the HES information using a simple postcode link. To maximize the match-rate the postcodes are forced across eight digits in each file. For example W1 1AA becomes W_1_1AA. Where postcodes have changed a retrospective file is also held that makes it possible to update old postcodes which may have been entered on the HES file.

\section{Results}

HES for Type 2 diabetes were matched against geodemographic codes for England. In this article we report on these figures aggregated for the UK. Table 1 and Table 2 demonstrate the geodemographic profile of Slough versus the UK average.

Table 3 demonstrates incidence of diabetes by 'MOSAIC Group' and Table 4 incidence of diabetes 
Table 1 Ranked MOSAIC Groups - Slough PCT and UK profiles

\begin{tabular}{|c|c|c|c|c|c|c|c|}
\hline & & $\begin{array}{l}\% \text { of } \\
\text { population } \\
\text { of Slough } \\
\text { in each } \\
\text { MOSAIC } \\
\text { Group }\end{array}$ & $\begin{array}{l}\% \text { of } \\
\text { population } \\
\text { of UK in } \\
\text { each } \\
\text { MOSAIC } \\
\text { Group }\end{array}$ & $\begin{array}{l}\text { Mean } \\
\text { average } \\
\text { index for } \\
\text { Slough } \\
\text { versus UK } \\
(100=\text { UK } \\
\text { average) }\end{array}$ & & & \\
\hline C & $\begin{array}{l}\text { Families who are successfully established in comfortable, } \\
\text { mature homes. Children are growing up and finances are easier. }\end{array}$ & 28.66 & 16.26 & 176 & $:$ & : & $\mathrm{z}$ \\
\hline$E$ & $\begin{array}{l}\text { Young, single and mostly well educated, these } \\
\text { people are cosmopolitan in tastes and liberal in attitudes. }\end{array}$ & 9.51 & 6.45 & 147 & & & \\
\hline $\mathrm{H}$ & $\begin{array}{l}\text { People who though not well-educated are practical and } \\
\text { enterprising and may well have exercised their right to buy. }\end{array}$ & 17.28 & 11.81 & 146 & & & \\
\hline B & $\begin{array}{l}\text { Families with focus on career and home, } \\
\text { mostly younger age groups now raising children. }\end{array}$ & 15.41 & 11.71 & 132 & & & \\
\hline D & $\begin{array}{l}\text { People living in close-knit inner city and manufacturing town } \\
\text { communities, responsible workers with unsophisticated tastes. }\end{array}$ & 18.54 & 16.14 & 115 & & & \\
\hline I & $\begin{array}{l}\text { Elderly people subsisting on meagre incomes in council } \\
\text { accommodation. }\end{array}$ & 1.67 & 2.85 & 59 & & & \\
\hline $\mathrm{F}$ & $\begin{array}{l}\text { People who are struggling to achieve rewards and are } \\
\text { mostly reliant on the council for accommodation and benefits. }\end{array}$ & 2.30 & 5.30 & 43 & & & \\
\hline A & $\begin{array}{l}\text { People with rewarding careers who live in sought } \\
\text { after locations, affording luxuries and premium quality products. }\end{array}$ & 3.31 & 10.41 & 32 & & & \\
\hline G & $\begin{array}{l}\text { Families on lower incomes who often live in large } \\
\text { council estates where there is little owner-occupation. }\end{array}$ & 2.11 & 6.89 & 31 & & & \\
\hline $\mathrm{J}$ & $\begin{array}{l}\text { Independent pensioners living in their own homes who are } \\
\text { relatively active in their lifestyles. }\end{array}$ & 1.21 & 6.70 & 18 & & & \\
\hline $\mathrm{K}$ & $\begin{array}{l}\text { People living in rural areas where country life has not been } \\
\text { influenced by urban consumption patterns. }\end{array}$ & 0.00 & 5.47 & 0 & & & \\
\hline \multicolumn{2}{|r|}{ Total } & 100 & 100 & 100 & & & \\
\hline
\end{tabular}


Table 2 Geodemographic breakdown for Slough PCT

\begin{tabular}{|c|c|c|c|c|c|}
\hline $\begin{array}{l}\text { Population } \\
\text { of Slough } \\
\text { in each } \\
\text { MOSAIC } \\
\text { Type }\end{array}$ & $\begin{array}{l}\% \text { of } \\
\text { population } \\
\text { of Slough } \\
\text { in each } \\
\text { MOSAIC } \\
\text { Type }\end{array}$ & $\begin{array}{l}\text { Population } \\
\text { of UK in } \\
\text { each } \\
\text { MOSAIC } \\
\text { Type }\end{array}$ & $\begin{array}{l}\% \text { of } \\
\text { Population } \\
\text { of UK in } \\
\text { each } \\
\text { MOSAIC } \\
\text { Type }\end{array}$ & Penalty \% & $\begin{array}{l}\text { Mean } \\
\text { average } \\
\text { index for } \\
\text { Slough } \\
\text { versus UK } \\
\text { (100 = UK } \\
\text { average) }\end{array}$ \\
\hline
\end{tabular}

\section{A Symbols of Success}

01 Global Connections

02 Cultural Leadership

03 Corporate Chieftains

04 Golden Empty Nesters

05 Provincial Privilege

06 High Technologists

07 Semi-Rural Seclusion

\section{B Happy Families}

08 Just Moving In

09 Fledgling Nurseries

10 Upscale New Owners

11 Families Making Good

12 Middle Rung Families

13 Burdened Optimists

14 In Military Quarters

\section{Suburban Comfort}

\section{Close to Retirement \\ 16 Conservative Values}

17 Small Time Business

18 Sprawling Subtopia

19 Original Suburbs

20 Asian Enterprise

\section{Ties of Community}

21 Respectable Rows

$\approx 22$ Affluent Blue Collar

23 Industrial Grit

24 Coronation Street

25 Town Centre Refuge

¿ 26 South Asian Industry

$\succsim 27$ Settled Minorities

\section{E Urban Intelligence}

28 Counter Cultural Mix 29 City Adventurers

30 New Urban Colonists

31 Caring Professionals

32 Dinky Developments

33 Town Gown Transition

N 34 University Challenge

u

5
2
4
23
4

$0 \quad 0.00$

0.01

430

2350

694

$\begin{array}{ll}6593 & 3.57\end{array}$

$610 \quad 0.50$

$2133 \quad 1.75$

$4138 \quad 3.40$

$6610 \quad 5.43$

0.00

340206

569707

774087

813753

1041885

1345396

1265420

321678

707526

1018040

1511942

2063265

1158699

135823

1875500

1639657

1781396

1981458

1547875

776569

25303

4.66

1.56

20.77

\section{9}

172

921
198

113

10827

4286

\section{$44 \quad 0.04$}

629

221

735

9962

0
0

\subsection{8}

0.14

0.76

0.16

3.52

0.52
0.18

0.60

0.00

0.00
$1449283 \quad 2.45$

$2000876 \quad 3.39$

\begin{tabular}{l}
$2359262 \quad 3.99$ \\
\hline
\end{tabular}

$1500575 \quad 2.54$

$503681 \quad 0.85$

$725936 \quad 1.23$

$991695 \quad 1.68$

$678424 \quad 1.15$

$561848 \quad 0.95$

$726135 \quad 1.23$

$606229 \quad 1.03$

$488323 \quad 0.83$

$456842 \quad 0.77$

$\begin{array}{ll}494045 & 0.50\end{array}$

\subsection{0}

0.00

0.07

0.03

0.04

0.17

0.03

0.22

0.65

0.06

0.14

0.20

0.57

0.00

0.07

0.03

0.01

0.29

0.12

3.26

0.42

0.01

0.04

0.01

0.02

1.49

0.43

0.01

0.11

0.03

0.12

2.04

0.00

0.00

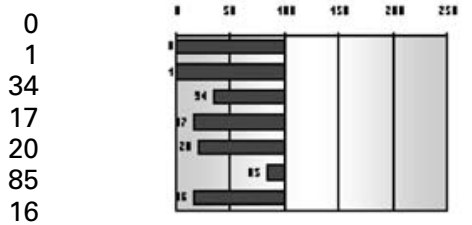

51 111 151 211 251

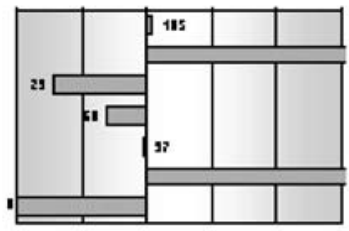

st

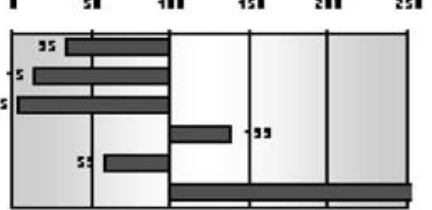

51 111 15t 311 25

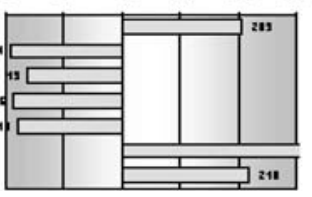

I 51 1II 151 211 251

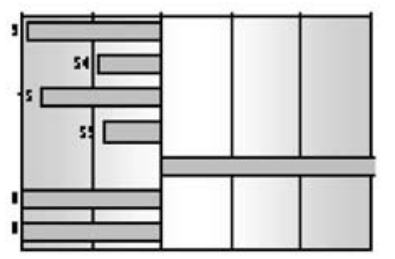




\section{F Welfare Borderline}

35 Bedsit Beneficiaries

36 Metro Multiculture

37 Upper Floor Families

38 Tower Block Living

39 Dignified Dependency

40 Sharing a Staircase

G Municipal Dependency

41 Families on Benefits

42 Low Horizons

43 Ex-industrial Legacy

H Blue Collar Enterprise

44 Rustbelt Resilience

45 Older Right to Buy

46 White Van Culture

47 NewTown Materialism

I Twilight Subsistence

48 Old People in Flats

49 Low Income Elderly

50 Cared for Pensioners

\section{J Grey Perspectives}

51 Sepia Memories

52 Childfree Serenity

53 High Spending Elders

54 Bungalow Retirement

55 Small Town Seniors

56 Tourist Attendants

\section{K Rural Isolation}

57 Summer Playgrounds

58 Greenbelt Guardians

59 Parochial Villagers

60 Pastoral Symphony

61 Upland Hill Farmers

Total

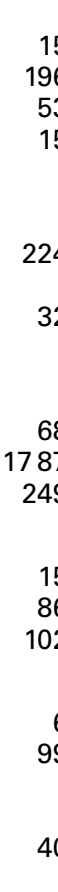

$\begin{array}{rr}0 & 0.00 \\ 150 & 0.12\end{array}$

150

1960

2246

0
320

320

0
681

68

2497

0.12
1.61

1.61
0.44

0.13

0.00

1.84

0.00

0.26

0.00

0.56

14.67

2.05

274729

990476

855135

184953

550905

271770

$\%$ of

Population

of UK in

each

MOSAIC

Type

838640

1698498

1534025

0.47

1.68

1.45

0.31

0.93

0.46

1950354

1501061

1988145

1536003

1.42

2.88

2.60

0.27

0.00

0.02

0.00

0.02

0.23

0.29

0.03

0.00

enalty \%

Mean

average

index for

Slough

versus UK

$(100=$ UK

average)

292729

3.30

2.54

3.37

2.60

0.00

0.05

0.90

0.16

0
7

111

141
13

13

0

130

0
10

$\begin{array}{lll}0.12 & 292729 & 0.50\end{array}$

0.05

$0.71 \quad 822995$

569032

1.39

0.10

0.18

\section{0}

605636

826085

618551

1486739

0.96

0.02

0.48

1.03

0.16

0.00

0.00

0.00

0.33

138570

1.05
2.52

2.52
0.23

0.03

138216

1058857

995000

794801

241036

0.23

0.00
0.00

0.00

0.00

59059067

1.79
1.68

135

0.41

121825

100

100

0.00

0.00

0.00

0.00

0.00

0.21

100
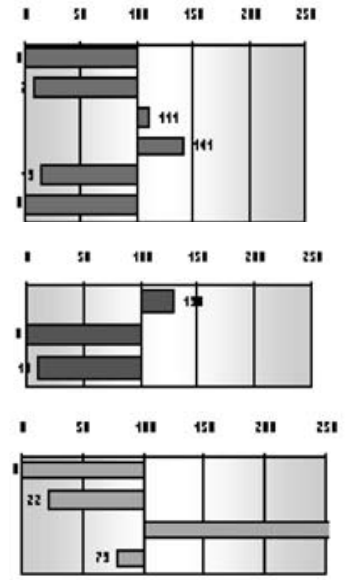

1 51 111 151 211 25
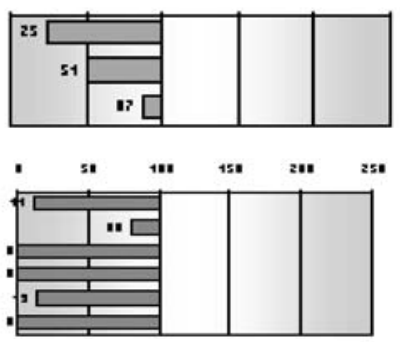

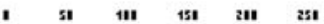

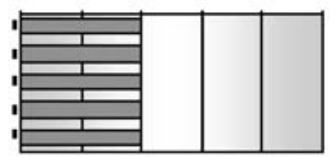


Table 3 UK Ranked MOSAIC Lifestyle Groups by incidence of diabetes

\begin{tabular}{|c|c|c|c|c|c|c|c|c|c|c|c|c|}
\hline & $\begin{array}{l}\text { Target } \\
\text { Incidence } \\
\text { of diabetes } \\
2 \text { across } \\
\text { each } \\
\text { MOSAIC } \\
\text { Group } \\
\text { in UK }\end{array}$ & $\begin{array}{l}\% \\
\text { Incidence } \\
\text { of diabetes } \\
2 \text { across } \\
\text { each } \\
\text { MOSAIC } \\
\text { Group } \\
\text { in UK }\end{array}$ & $\begin{array}{l}\text { Base } \\
\text { Population } \\
\text { of UK in } \\
\text { each } \\
\text { MOSAIC } \\
\text { Group }\end{array}$ & $\begin{array}{l}\% \\
\text { Population } \\
\text { of UK in } \\
\text { each } \\
\text { MOSAIC } \\
\text { Group }\end{array}$ & $\begin{array}{l}\text { Penalty \% } \\
\text { penetration } \\
\text { of diabetes } \\
2 \text { across } \\
\text { each } \\
\text { MOSAIC } \\
\text { Group }\end{array}$ & $\begin{array}{l}\text { Index } \\
\text { Mean } \\
\text { average } \\
\text { deviation } \\
\text { score for } \\
\text { diabetes in } \\
\text { UK MOSAIC } \\
\text { Groups } \\
\text { (average = 100) }\end{array}$ & & & & & & \\
\hline I Twilight Subsistence & 63477 & 8.01 & 1684756 & 2.85 & 3.77 & 281 & & & & & & \\
\hline J Grey Perspectives & 79389 & 10.02 & 3958671 & 6.70 & 2.01 & 149 & & sı & 111 & 151 & z"I & $2 s !$ \\
\hline $\begin{array}{l}\text { G Municipal } \\
\text { Dependency }\end{array}$ & 76503 & 9.65 & 4071163 & 6.89 & 1.88 & 140 & & & & & & \\
\hline F Welfare Borderline & 50464 & 6.37 & 3127968 & 5.30 & 1.61 & 120 & & & & 149 & & \\
\hline D Ties of Community & 143547 & 18.11 & 9531308 & 16.14 & 1.51 & 112 & & & & 41 & & \\
\hline $\begin{array}{l}\text { H Blue Collar } \\
\text { Enterprise }\end{array}$ & 102748 & 12.96 & 6975563 & 11.81 & 1.47 & 110 & & & & & & \\
\hline $\begin{array}{l}\text { C Suburban } \\
\text { Comfort }\end{array}$ & 120586 & 15.21 & 9602455 & 16.26 & 1.26 & 94 & & & & & & \\
\hline K Rural Isolation & 30458 & 3.84 & 3227910 & 5.47 & 0.94 & 70 & & & & & & \\
\hline E Urban Intelligence & 33292 & 4.20 & 3811846 & 6.45 & 0.87 & 65 & & T & & & & \\
\hline $\begin{array}{l}\text { A Symbols of } \\
\text { Success }\end{array}$ & 49425 & 6.24 & 6150454 & 10.41 & 0.80 & 60 & & 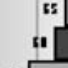 & & & & \\
\hline B Happy Families & 42672 & 5.38 & 6916973 & 11.71 & 0.62 & 46 & & 4 & & & & \\
\hline Total & 792561 & 100 & 59059067 & 100 & 1.34 & 100 & & & & & & \\
\hline
\end{tabular}




\begin{tabular}{|c|c|c|c|c|c|c|}
\hline Ranked MOSAICTypes & $\begin{array}{l}\text { Target } \\
\text { Incidence } \\
\text { of diabetes } \\
2 \text { across each } \\
\text { MOSAIC } \\
\text { Type in UK }\end{array}$ & $\begin{array}{l}\% \\
\text { Incidence } \\
\text { of diabetes } \\
2 \text { across each } \\
\text { MOSAIC } \\
\text { Type in UK }\end{array}$ & $\begin{array}{l}\text { Base } \\
\text { Population } \\
\text { of UK in each } \\
\text { MOSAICType }\end{array}$ & $\begin{array}{l}\% \\
\text { Population } \\
\text { of UK in each } \\
\text { MOSAICType }\end{array}$ & $\begin{array}{l}\text { Penalty \% } \\
\text { penetration } \\
\text { of diabetes } \\
2 \text { across each } \\
\text { MOSAICType }\end{array}$ & $\begin{array}{l}\text { Index } \\
\text { Mean average } \\
\text { deviation score } \\
\text { for diabetes in } \\
\text { UK MOSAICTypes } \\
\text { (average }=100 \text { ) }\end{array}$ \\
\hline 50 Cared for Pensioners & 32984 & 416 & 569032 & 096 & 580 & 432 \\
\hline 48 Old People in Flats & 15013 & 1.89 & 292729 & 0.50 & 5.13 & 382 \\
\hline 51 Sepia Memories & 11198 & 1.41 & 283090 & 0.48 & 3.96 & 295 \\
\hline 26 South Asian Industry & 21322 & 2.69 & 725936 & 1.23 & 2.94 & 219 \\
\hline 54 Bungalow Retirement & 15910 & 2.01 & 618551 & 1.05 & 2.57 & 192 \\
\hline 39 Dignified Dependency & 13950 & 1.76 & 550905 & 0.93 & 2.53 & 189 \\
\hline 43 Ex-industrial Legacy & 35468 & 4.48 & 1534025 & 2.60 & 2.31 & 172 \\
\hline 49 Low Income Elderly & 15480 & 1.95 & 822995 & 1.39 & 1.88 & 140 \\
\hline 20 Asian Enterprise & 14570 & 1.84 & 776569 & 1.31 & 1.88 & 140 \\
\hline 37 Upper Floor Families & 15584 & 1.97 & 855135 & 1.45 & 1.82 & 136 \\
\hline $\mathbf{2 5}$ Town Centre Refuge & 9100 & 1.15 & 503681 & 0.85 & 1.81 & 135 \\
\hline 38 Tower Block Living & 3309 & 0.42 & 184953 & 0.31 & 1.79 & 133 \\
\hline 42 Low Horizons & 30127 & 3.80 & 1698498 & 2.88 & 1.77 & 132 \\
\hline 55 Small Town Seniors & 26171 & 3.30 & 1486739 & 2.52 & 1.76 & 131 \\
\hline 45 Older Right to Buy & 26114 & 3.29 & 1501061 & 2.54 & 1.74 & 130 \\
\hline 56 Tourist Attendants & 2410 & 0.30 & 138570 & 0.23 & 1.74 & 130 \\
\hline 24 Coronation Street & 25955 & 3.27 & 1500575 & 2.54 & 1.73 & 129 \\
\hline 52 Childfree Serenity & 10088 & 1.27 & 605636 & 1.03 & 1.67 & 124 \\
\hline 53 High Spending Elders & 13612 & 1.72 & 826085 & 1.40 & 1.65 & 123 \\
\hline 16 Conservative Values & 26504 & 3.34 & 1639657 & 2.78 & 1.62 & 120 \\
\hline 46 White Van Culture & 30551 & 3.85 & 1988145 & 3.37 & 1.54 & 115 \\
\hline 36 Metro Multiculture & 14947 & 1.89 & 990476 & 1.68 & 1.51 & 112 \\
\hline 27 Settled Minorities & 13621 & 1.72 & 991695 & 1.68 & 1.37 & 102 \\
\hline 47 New Town Materialism & 20946 & 2.64 & 1536003 & 2.60 & 1.36 & 102 \\
\hline 23 Industrial Grit & 31854 & 4.02 & 2359262 & 3.99 & 1.35 & 101 \\
\hline
\end{tabular}


by 'MOSAIC Type'. Table 3 and Table 4 reveal what are perhaps the most important results of this analysis. Those 'groups' and 'types' that have the highest Type 2 counts are the ones with the highest indices. An index of 100 indicates the UK average penetration of the disease. The Groups with the highest penetrations of Type 2 diabetes (over 100) are, in order, 'Twilight Subsistence', 'Grey Perspectives', 'Municipal Dependency', 'Welfare Borderline', 'Ties of Community', 'Blue Collar Enterprise'. People who live in areas characterized as 'Twilight Subsistence' have a high-average age, and a lower than average income. They may not be well educated, and will typically have lower social class backgrounds. These people may not be particularly mobile and are likely to have low aspirations with the remainder of their lives. 'Grey Perspectives', though of similar advanced years, will be better off and better educated than the 'Twilight Subsistence' group, and it is interesting to note the dramatic drop in diabetes that occurs. While age is the key underlying factor of the top two groups, the next two, 'Municipal Dependency' and 'Welfare Borderline' groups comprise people who have very low average incomes and low horizons in life. They exhibit predominantly working class cultures that will strongly influence attitudes to diet and exercise, and will be less well educated than UK averages. The concern with these groups lies particularly with their modest average age, indicating poor weight control in early stages in life.
'Ties of community' and 'Blue Collar Enterprise' are also working class-based cultural groups with distinct sub-cultures, but once more likely to be characterized by strong socially driven attitudes to diet and exercise that will need hard work to break down. However these groups have indices that are only just above the national average.

At the bottom of the chart 'Rural Isolation', 'Urban Intelligence', 'Symbols of Success' and finally 'Happy Families' all have incidences of Type 2 diabetes that are much lower than the national average, perhaps suggesting that less resources will need to be deployed in these population clusters.

Table 4, highlights the same data as Table 3, this time split into 'MOSAIC Types', which are smaller clusters with more 'extreme' underlying demographics. As can be seen, the indices can be much higher or lower than for Groups, with an index of 432 indicating an incidence of diabetes of 4.32 times the national average. This has important implications for the extra return on investment that may be expected for tightly targeted activities. Finally, it is interesting to note the high indices attached to predominantly Asian geographic types, suggesting the adverse impact Asian-based diets have had on prevalence of Type 2 diabetes.

Table 5 illustrates how the combination of datasets MOSAIC and HES, can allow one to drill down to postcode sectors to highlight 'hotspots' for Type 2 diabetes prevalence. In this case study for Slough

Table 5 Demonstration of geodemographics as a targeting system: Slough PCT - Zone Ranking

\begin{tabular}{|c|c|c|c|c|c|c|}
\hline Postal sector & $\begin{array}{l}\text { D43 Settled but poor older } \\
\text { people in low-rise social } \\
\text { housing, often found in } \\
\text { declining industrial areas }\end{array}$ & $\%$ & Slough & $\%$ & Penalty & Index \\
\hline SL 21 Long Readings Lane, Slough & 143 & 57.43 & 12,484 & 11.1 & 1.145 & 515 \\
\hline SL 38 Sutton, Slough & 106 & 42.57 & 14624 & 13.1 & 0.725 & 326 \\
\hline SL 11 Upton, Slough & 0 & 0.00 & 4340 & 3.9 & 0.000 & 0 \\
\hline SL 12 Chalvey, Slough & 0 & 0.00 & 12002 & 10.7 & 0.000 & 0 \\
\hline SL 13 Salt Hill, Slough & 0 & 0.00 & 12319 & 11.0 & 0.000 & 0 \\
\hline SL 14 Manor Park, Slough & 0 & 0.00 & 890 & 0.8 & 0.000 & 0 \\
\hline SL 15 Dorney, Slough & 0 & 0.00 & 10343 & 9.2 & 0.000 & 0 \\
\hline SL 16 Blumfield $\mathrm{Cr}$, Slough & 0 & 0.00 & 6142 & 5.5 & 0.000 & 0 \\
\hline SL 19 Wood Lane, Slough & 0 & 0.00 & 2630 & 2.3 & 0.000 & 0 \\
\hline SL 22 Lynch Hill, Slough & 0 & 0.00 & 7429 & 6.6 & 0.000 & 0 \\
\hline SL 25 Petersfield Road, Slough & 0 & 0.00 & 13677 & 12.2 & 0.000 & 0 \\
\hline SL 30 Colnbrook, Slough & 0 & 0.00 & 3533 & 3.2 & 0.000 & 0 \\
\hline SL 37 Slough, Slough & 0 & 0.00 & 11573 & 10.3 & 0.000 & 0 \\
\hline Total & 249 & 100.00 & 111986 & 100.0 & 0.222 & 100 \\
\hline
\end{tabular}




\section{Jane Powell et al.}

PCT area down to a street level which is powerful information on which to base resource allocation and targeting decisions at a policy level.

The combination of datasets method is very useful to all PCTs in terms of identification of at risk groups and targeting of resources and effort. Table 6 illustrates 'hotspots' and low-spots' at PCT area level. This can aid primary care professionals to recognize the need to target or not target scarce resources at Type 2 diabetes prevention vis-a-vis other competing uses of scarce resources.

\section{Discussion}

\section{Limitations of the approach}

Our analysis has highlighted age, weight, ethnicity and poverty, as the key variables impacting on

Table 6 Predicted prevalence of Type 2 diabetes by PCT

\begin{tabular}{|c|c|c|c|}
\hline Ranking & PCT & $\begin{array}{l}\text { Estimated number of } \\
\text { people with diabetes }\end{array}$ & Total population \\
\hline 231 & Staffordshire Moorlands 5HR & 4421 & 116076 \\
\hline 232 & Mansfield District 5AM & 4403 & 96162 \\
\hline 233 & South Liverpool $5 \mathrm{HC}$ & 4386 & 99091 \\
\hline 234 & Chiltern and South Bucks 5G4 & 4381 & 166544 \\
\hline 235 & Exeter 5FR & 4377 & 130402 \\
\hline 236 & Hartlepool 5D9 & 4372 & 88004 \\
\hline 237 & Sedgefield 5KE & 4360 & 89734 \\
\hline 238 & Doncaster East 5EK & 4351 & 109222 \\
\hline 239 & Broadland 5JL & 4348 & 121016 \\
\hline 240 & Ashfield 5FA & 4338 & 90723 \\
\hline 241 & Slough 5DM & 4325 & 121337 \\
\hline 242 & North Peterborough 5AF & 4292 & 99651 \\
\hline 243 & Witham, Braintree and HalsteadTAG & 4268 & 125892 \\
\hline 244 & Basildon 5GR & 4251 & 101853 \\
\hline 245 & South Wiltshire 5DJ & 4236 & 119457 \\
\hline 246 & West Wiltshire 5DH & 4233 & 121969 \\
\hline 247 & Langbaurgh 5KN & 4228 & 97144 \\
\hline 248 & Hambleton and Richmondshire $5 \mathrm{KH}$ & 4226 & 117767 \\
\hline 249 & Derwentside 5KA & 4193 & 89331 \\
\hline 250 & Cherwell Vale 5DV & 4188 & 129011 \\
\hline 251 & Oldbury and Smethwick 5MG & 4174 & 89147 \\
\hline \multicolumn{4}{|c|}{ Top 10 PCTs } \\
\hline 319 & Newbury and Community 5DK & 3415 & 89151 \\
\hline 320 & Fylde $5 \mathrm{HE}$ & 3166 & 71100 \\
\hline 321 & Maldon and South Chelmsford 5GL & 3145 & 83887 \\
\hline 322 & North East Oxfordshire 5DT & 2930 & 67189 \\
\hline 323 & Eden Valley 5D5 & 2559 & 68703 \\
\hline 324 & Royston, Buntingford and Bishop's Stortford 5GK & 2541 & 64047 \\
\hline 325 & Uttlesford 5GN & 2454 & 68980 \\
\hline 326 & Western Isles 15 & 1138 & 25940 \\
\hline 327 & Shetland 14 & 911 & 21910 \\
\hline 328 & Orkney 13 & 729 & 19111 \\
\hline \multicolumn{4}{|c|}{ Bottom 10 PCTs } \\
\hline 1 & BroTaf OW2 & 34916 & 709662 \\
\hline 2 & Lothian 05 & 33647 & 783081 \\
\hline 3 & Greater Glasgow 09 & 32237 & 866755 \\
\hline 4 & Eastern (NI) 9501 & 31782 & 662066 \\
\hline 5 & North Wales QW4 & 31177 & 668067 \\
\hline 6 & Gwent OW1 & 29574 & 559650 \\
\hline 7 & Lanarkshire 10 & 28929 & 552164 \\
\hline 8 & Morgannwg QW5 & 24887 & 488626 \\
\hline 9 & Grampian 02 & 23706 & 521377 \\
\hline 10 & Dyfed Powys QW3 & 21113 & 496391 \\
\hline
\end{tabular}

Primary Health Care Research and Development 2007; 8: 22-35 
Type 2 diabetes. In this analysis it is important not to overclaim diabetes as a surrogate for obesity. This is true amongst younger age groups, but for over $65 \mathrm{~s}$ diabetes may occur more frequently regardless of the obesity of individuals. Of more interest therefore is the rather stark segmentation that emerges according to class, with 'lower social class' groups much more prone to obesity than 'middle classes'. Perhaps the most important finding, is the exhibit that segmentation systems based on demographics and geography seem to offer precise targeting opportunities and hence a powerful way for focusing scarce health resources. Another qualification that might limit the power of combining geodemographic and HES data, is that individual attitudes and beliefs concerning health status are captured indirectly rather than directly using this approach.

Interestingly, while there are instances of psychological unhappiness being linked to overeating, the World Health Organisation (WHO) suggest that by and large overeating is not the key issue leading to obesity, as we eat less on average in terms of calorific value, today, than we did 50 years ago. The central issue is lack of physical exercise, within the context of westernized lives being made more and more sedentary with respect to how we live our everyday lives. A typical westernized life now involves a lack of in-built exercise to such a profound extent that most physical activity involves 'artificial' intervention in daily routines. If this line of argument is accepted, and it is by the WHO, then the current obsession with dieting is tackling the problem from the wrong end (WHO, 2004). The role of social marketing is to work out how to design and implement behavioural intervention programmes that have the best chance of success in increasing physical activity. However, these interventions would also need to be tailored appropriately to their audience if they are to be successful in motivating and sustaining people in increased physical activity and again household MOSAIC would be a useful tool to facilitate appropriate approaches tailored to the specific sub-populations.

\section{Communications channels}

The approach identified in this article is not complete without some discussion of the communications channels which use of MOSAIC profiles open up, as these are as crucial to success of targeting. The best media will be those which facilitate a direct approach that can use the segmentation to best advantage. New media such as Email or mobile have yet to be well linked with geodemographics, so the best traditional channels include telephone canvassing, door-to-door and direct mail. Door-to-door is particularly well suited to geodemographics, as door-to-door media is itself geographically based (Tapp, 2005).

One of the Wanless Report's main themes is to encourage deprived or marginalized communities to improve their own health. MOSAIC analysis clearly shows how important deprived communities are at the front line of the obesity issue in the UK. Primary care professionals therefore could have a role in using these communication channels to support and empower deprived and marginalized communities to improve their own health. For those 'at risk' of Type 2 diabetes our behavioural intervention model for reducing obesity suggests these communication channels are used to mount a two-pronged initiative that 'targets' both diet (a little) and physical activity (mostly). As far as primary care professionals are concerned door-to-door canvassing in the form of 'brief intervention' might be both supportive and cautionary in advising overweight or obese people in terms of sudden increased physical activity and improved diet. If more information is required, direct mail, with its extra physical space, may be better suited.

\section{Future work}

Figure 2 is offered as a way of structuring the causal linkages, and may be a start point for future research.

It is vital that the public are involved in the implementation of a social marketing strategy to reduce obesity. Social marketers emphasize that 'listening to the consumer' or 'consumer involvement' are all important in terms of initiating sustained behaviour changes in consumers (Lefebvre and Flora, 1988; Naidoo and Wills, 2005). This stance is in keeping with the current view of public health professionals; that they are engaged in partnership with users of services and that they should enable 'user involvement' in the delivery of public healthcare.

\section{Conclusion}

This article has reported on a case study approach in which HES for Type 2 diabetes were combined Primary Health Care Research and Development 2007; 8: 22-35 


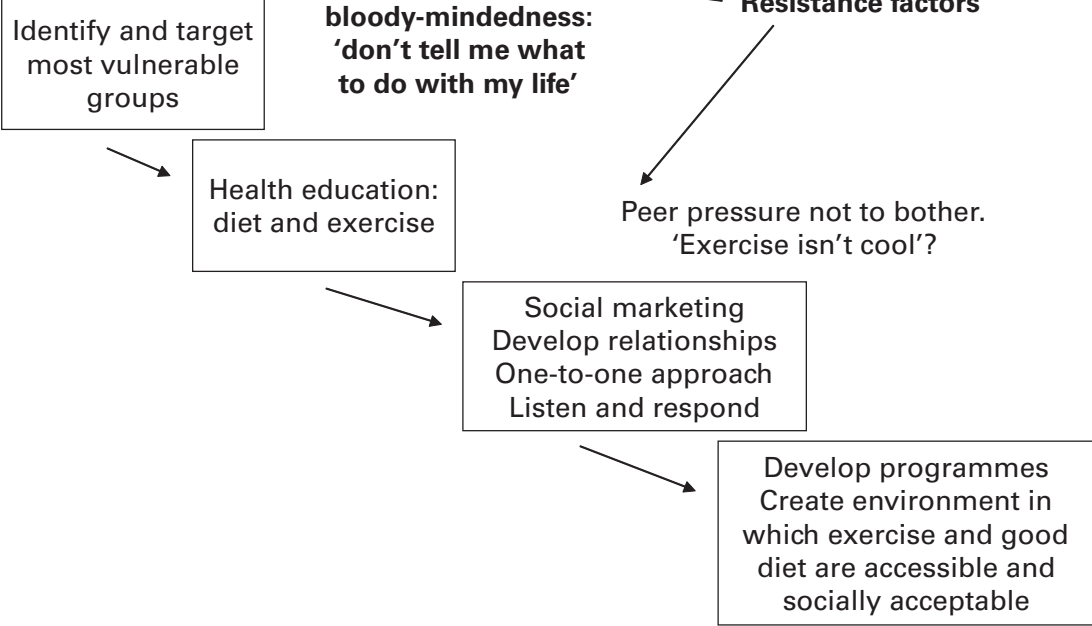

Figure 2 A behavioural intervention model for reducing obesity

with household MOSAIC to identify neighbourhood, wards and streets for targeted interventions in health prevention of Type 2 diabetes in the area covered by Slough PCT. The theoretical and practical benefits of the combination of NHS data and geodemographic profiling seem to be considerable in terms of identification, targeting and use of communication channels for 'getting health messages across' in an appropriate and tailored way. Primary healthcare professionals could use the approach outlined in this article to devise tailored behavioural interventions including social marketing to various segments of the population at country, city, towns, ward, neighbourhood and street level. Changing one's life to overcome overweight and obesity is very difficult. There are clearly big social, cultural and psychological barriers to reducing obesity. The first premise of social marketing is that these barriers must be understood before attempting behaviour change. From a practical standpoint, tools such as MOSAIC can be combined with routine datasets to allow precise targeting of particularly vulnerable groups. This means scarce resources can be precisely deployed to areas of most need. MOSAIC can in turn aid public health professionals and social marketers to understand the geodemographic factors that influence lifestyles that lead to obesity; helping in efficient resource allocation and the design of appropriate programmes and interventions that are sent through appropriate communication channels.

\section{Acknowledgements}

Jane Powell, Alan Tapp and Judy Orme were supported by internal University of the West of England, Bristol funds. Marc Farr, Dr Foster, London, UK was employed at Experian UK when some of the analysis for this article was undertaken. Thanks to Experian UK, Business Strategies Division for providing access to the data on which this article is based.

\section{References}

Chief Medical Officer. 2002: Annual report 2002. London: Department of Health.

Department of Health. 2003: The health survey for England 2002. London: HMSO.

Department of Health. 2004: Choosing health: making healthy choices easier. London: HMSO.

Diabetes UK. 2005: Type 2 diabetes and obesity: a heavy burden. London: Diabetes UK.

Farr, M. and Evans, A. 2005: Identifying unknown diabetics using geodemographics and social marketing. Journal of Direct Data and Digital Marketing Practice 7, 47-58. 
Hastings, G. and Saren, M. 2003: Introduction to a special issue on social marketing. Marketing Theory 3, 291-92.

House of Commons Health Committee. 2004: Obesity. London: The Stationary Office.

International Obesity Taskforce. 2002: Retrieved 24 April 2004 from http://www.iotf.org

Lefebvre, R.C. and Flora, J.A. 1988: Social marketing and public health intervention. Health Education Quarterly 15, 299-315.

Mulvihill, C. and Quigley, R. 2003: The management of obesity and overweight: an analysis of reviews of diet, physical activity and behavioural approaches. London: Health Development Agency.

Naidoo, J. and Wills, J. 2005: Public health and health promotion: developing practice. Edinburgh: Bailliere Tindall Elsevier.

National Social Marketing Centre for Excellence. 2005: Social marketing pocket guide. London: Department of Health.
Office of National Statistics. 2003: The national diet and nutrition survey: adults aged 19-64 years. Newport: ONS.

Royal College of Physicians Royal College of Paediatrics and Child Health and Faculty of Public Health. 2004: Storing up problems: the medical case for a slimmer nation. Report of a joint working group. London: Royal College of Physicians.

Tapp, A. 2005: Principles of direct and database marketing. FT Prentice Hall: Harlow.

Wanless, D. 2002: Securing our future health: taking a long term view. London: HM-Treasury.

Wanless, D. 2004: Securing good health for the whole population. London: HM-Treasury.

World Health Organisation. 2004: Global strategy on diet, physical activity and health. Geneva: World Health Organisation. 